\title{
MATHEMATICAL PERSPECTIVES
}

BULLETIN (New Series) OF THE

AMERICAN MATHEMATICAL SOCIETY

Volume 51, Number 2, April 2014, Pages 329-334

S 0273-0979(2014)01450-8

Article electronically published on January 27, 2014

\section{ABOUT THE COVER: HILBERT AND THE PARIS ICM}

\author{
GERALD L. ALEXANDERSON
}

Mathematicians are expected to write persuasive and logical arguments. But eloquent and memorable turns of phrase? Perhaps not. All one needs to do is read G. H. Hardy's A Mathematician's Apology, however, to know that a mathematician can write brilliant prose. David Hilbert was another powerful mathematician with wide interests, but also a master of memorable language, though for Englishspeaking readers, his words are filtered through various translators. Several works about Hilbert begin with the opening of his famous plenary address, when he was 38, at the Second International Congress of Mathematicians in 1900 in Paris. It was modestly titled "Problèmes Futurs des Mathématiques", later reduced to "Mathematical Problems". He listed 23 questions to challenge mathematicians during the 20th century, and a remarkably prescient set of problems it was.

His talk was given in German but it appeared in French in the Proceedings of that Congress [4] two years later, probably a gesture of respect to the host country. Those Proceedings appeared in 1902, the same year the problems were published in English in an issue of the Bulletin of the American Mathematical Society. Of course, with each translation it may have lost some of the power of the original. Hilbert had time to describe only 10 of the 23 problems in the plenary session, and listeners had to wait for the full descriptions of the rest until they came out in the Göttinger Nachrichten. The translation into English was the work of Mary Winston Newson, the first American woman to go abroad for a Ph.D. in mathematics, supervised by Felix Klein at Göttingen. And equally remarkable was the choice of Charlotte A. Scott of Bryn Mawr to report on the Congress for the AMS Bulletin [1, p. 9]. Just what Hilbert had to do with these prominent roles for women is not clear, but it is entirely consistent with Hilbert's championing the case of Emmy Noether when she was considered for a promotion to Privatdozent at Göttingen only to meet with objections of the sort: "How can it be allowed that a woman become a Privatdozent? Having become a Privatdozent, she can then become a professor and 


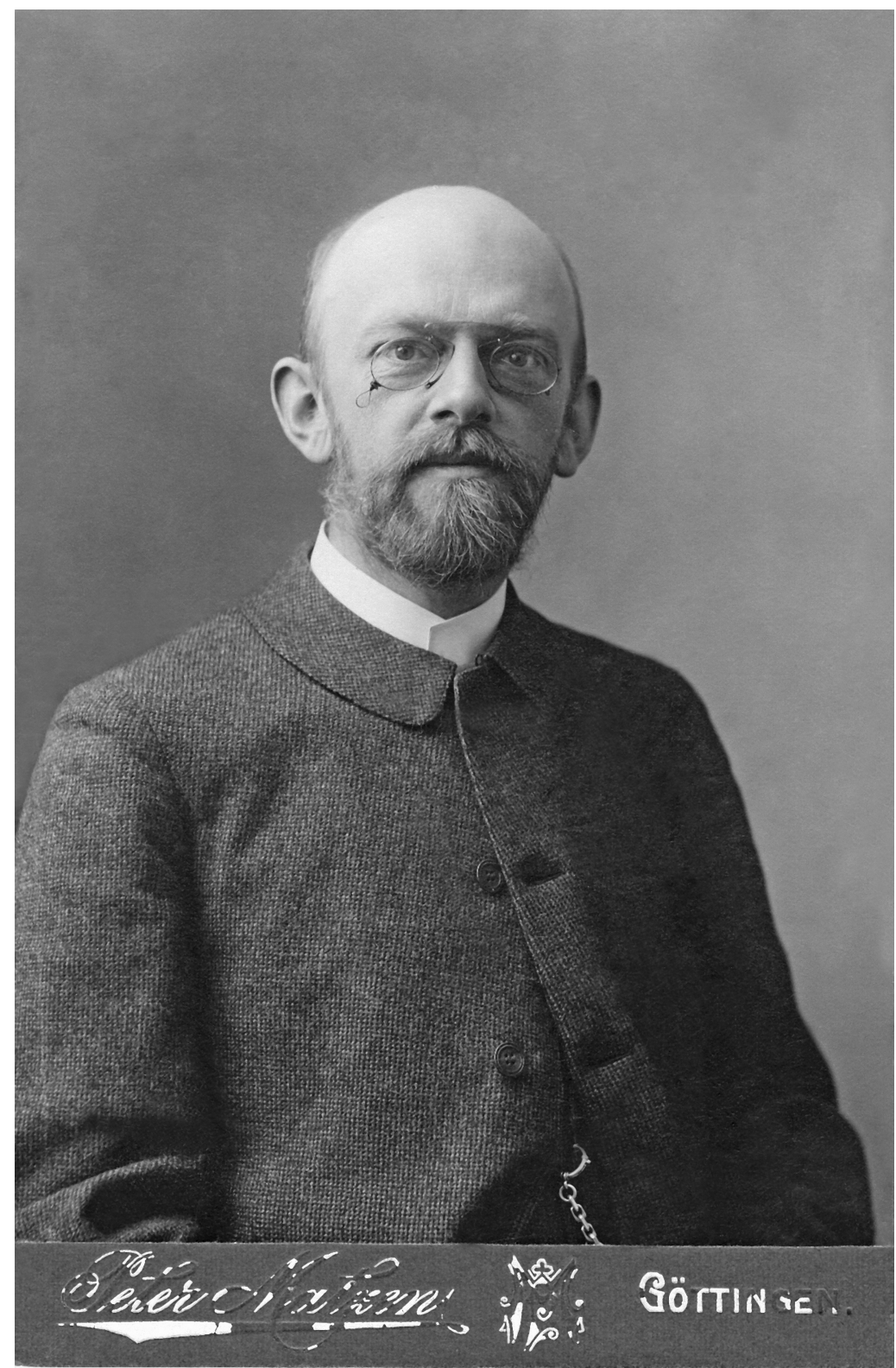

Figure 1. Clear Copy of the COver: David Hilbert, 1905.

a member of the University Senate. Is it permitted that a woman enter the Senate? ... What will our soldiers think when they return to the University and find that they are expected to learn at the feet of a woman?" Hilbert replied, "Meine Herren, I do not see that the sex of the candidate is an argument against her admission as a Privatdozent. After all, the Senate is not a bath-house" [7, p. 143].

The opening of the Paris Congress was scheduled to coincide with a world's fair, the Exposition Universelle. This followed the precedent set by the 1893 meetings 
held on the occasion of Chicago's World's Columbian Exposition of the same year. That fair was held to celebrate Columbus's discovery of America, but there were construction delays and financial problems that caused it to open a year late. The mathematical meetings in Chicago were modest. Only Felix Klein of Göttingen came from Europe, but he brought with him papers from Hermite, Hilbert, Hurwitz, Minkowski, Max Noether, Pincherle, Netto, and Pringsheim - a good cross section of European mathematics. Among Americans, there were Bolza, Maschke, and E. H. Moore from the University of Chicago [1, p. 3]. These meetings were the model for the first official International Congress that took place in Zurich four years later.

At the Paris Congress Hilbert began, "Who of us would not be glad to lift the veil behind which the future lies hidden; to cast a glance at the next advances of our science and at the secrets of its development during future centuries? What particular goals will there be towards which the leading mathematical spirits of coming generations will strive? What new methods and new facts in the wide and rich field of mathematical thought will the new centuries disclose?" [7, p. 74].

The easiest problem on Hilbert's list was probably the third, to prove that the Bolyai-Gerwin theorem on the equidecomposability of polygons in the plane does not carry over to three-space. It was proved soon after the Congress by the 22year old Max Dehn. Other problems were much more difficult, such as the eighth which contained the Riemann Hypothesis, unsolved to this day. These were both problems similar to the tenth, solved in the 1980s by J. Robinson, M. Davis, and Y. Matijasevic who showed it is not possible to find an algorithm that could apply to the solution of arbitrary Diophantine equations. When these problems are solved, either with a proof of a conjecture or an example of why something is not true, the problem is effectively "solved". Hilbert's list has "problems" of another type, however, one of these being the sixth. With Hilbert's success in earlier years in the task of axiomatizing geometry (1898-1903), he suggested treating mathematical physics similarly. This sixth problem quickly split into two parts, one putting probabilistic problems in mathematical physics on an axiomatic footing, the other doing something similar for mechanics, specifically problems around the Boltzmann equation. Much progress on the first was made early on by Kolmogorov and others, while on the second part work continues to the present time, as we can see from two contributions (one from A. Gorban and I. Karlin and the other from L. SaintRaymond) that appear in this issue of the Bulletin. Clearly there is more to be done; there are still open questions, clear from a comment in the first of these: "To the best of our knowledge, now the answers to these three questions are: (1) sometimes, (2) not always, (3) possibly."

A naïve question is often asked: "How many of Hilbert's problems have now been solved?" It is clearly not easy to say. The understanding of some of the problems is still evolving. A survey of the "unsolved" problems was the topic of a symposium at Northern Illinois University in 1974, with contributions by distinguished experts in the various fields appearing in a proceedings volume. The essay on the sixth problem was written by the eminent Princeton physicist, A. S. Wightman [9, pp. 147-240]. A more recent, less technical survey, is Yandell's The Honor Code/Hilbert's Problems and Their Solvers, accessible to non-specialists and with descriptions of the status of problems up to 2002 [10. The book won the Euler Book Prize in 2008. 
The closing of Hilbert's Paris talk was “... with the extension of mathematical knowledge will it not finally become impossible for the single investigator to embrace all departments of this knowledge? In answer let me point out how thoroughly it is ingrained in mathematical science that every real advance goes hand in hand with the invention of sharper tools and simpler methods which at the same time assist in understanding earlier theories and cast aside older more complicated developments. It is therefore possible for the individual investigator, when he makes these sharper tools and simpler methods his own, to find his way more easily in the various branches of mathematics than is possible in any other science. The organic unity of mathematics is inherent in the nature of this science, for mathematics is the foundation of all exact knowledge of natural phenomena. That it may completely fulfil this high mission, may the new century bring it gifted masters and many zealous and enthusiastic disciples" [4, p. 436].

Though Hilbert's list may well have been the most important address given at any of the International Congresses of Mathematicians, it was far from being the last of his contributions in this area, though there was a gap in the history mainly caused by the two world wars. Details appear in [1] and [6]. Hilbert attended and spoke at the Congress in 1904 in Heidelberg, on something not quite as broad as the 23 problems - the foundations of logic and arithmetic - but he does not appear on the roster of Congress members in Rome in 1908, nor that of Cambridge (England) in 1912 (though he was a member of the organizing committee). During the period between 1912 and 1920 the congresses were suspended. It was at Bologna in 1928 that Hilbert played a major role in trying to make it possible for Germans once again to be invited to a Congress - they were very pointedly not invited to those in Strasbourg and Toronto [2]. Though emotions still ran high, invitations to Bologna were sent to likely German delegates, but there were some who chose not to attend-Bieberbach, for one. Hilbert waxed eloquent on the subject, trying to convince colleagues to attend in 1928. At the opening Hilbert spoke with some passion: "It makes me very happy that after a long, hard time all the mathematicians of the world are represented here. That is as it should be and as it must be for the prosperity of our beloved science. Let us consider that we as mathematicians stand on the highest pinnacle of the cultivation of the exact sciences. We have no other choice than to assume this highest place, because all limits, especially national ones, are contrary to the nature of mathematics. It is a complete misunderstanding of our science to construct differences according to people and races, and the reasons for which this has been done are very shabby ones. Mathematics knows no races ... For mathematics the whole cultural world is a single country" [3, p. 83].

In Bologna Hilbert gave his major address in German, on the foundations of mathematics, joining with others in giving major talks (J. Hadamard, E. Borel, O. Veblen, W. H. Young, H. Weyl. T. von Kármán, M. Fréchet, and V. Volterra, along with a few lesser known Italians. He was in good company. But it was a curious meeting on various counts. G. D. Birkhoff's plenary address was his famous talk about mathematics and art, delivered in the Palazzo Vecchio in Florence. (The Bologna Congress was a rather peripatetic one.) The choice of the honorary president of the Congress was Benito Mussolini (though there is no evidence that he ever showed up at any meetings!) Volterra in Rome in 1908 had been greeted by King Vittorio Emanuele III! Birkhoff, who was the head of the American delegation, delivered his remarks at the opening session in Italian and his later plenary address 
was in French. But the Rector of the University topped them all by addressing the members of the Congress in Latin.

Two years later Hilbert returned to Königsberg, where he had received his doctorate under the supervision of Lindemann. He was shifting into retirement and delivered on this occasion a lecture at the University of Königsberg, his alma mater. The lecture was one of the most memorable of his career: Naturerkennen und Logik (the understanding of nature and logic). Though he had visited his native citythe city of Kant, Jacobi, and Minkowski - this was a special visit organized by Reidemeister and Szegö to honor Hilbert. An honorary citizenship was bestowed on him. He began his address with "The understanding of nature and life is our noblest task." Reid summarized it by saying that "in the final part of his speech, Hilbert carefully made the point that in spite of the importance of the applications of mathematics, these must never be made the measure of its value. He concluded with that defense of pure mathematics which he had wanted so long ago to make in answer to the speech given by Poincaré at the first International Congress of Mathematicians" [in Zurich]. In Hilbert's words: "Pure number theory is that part of mathematics for which up to now no application has ever been found. But it is number theory which was considered by Gauss [who himself made untold contributions to applied mathematics] as the queen of mathematics ..." [7, 192-196]. (Hardy would have agreed!) The talk closed with the phrase for which Hilbert is best known: "Wir müssen wissen. Wir werden wissen." [We must know. We shall know.]

The latter part of that speech still exists on a recording, a copy of which is slipped into an envelope at the back of Reidemeister's book on Hilbert 88. It is thrilling to hear those words spoken by Hilbert himself.

Hilbert died in 1943, having set in 1900 in Paris an agenda for mathematicians in the 20th century, but what is still unsolved from the list remains as a challenge for the 21st.

\section{REFERENCES}

[1] Donald J. Albers, G. L. Alexanderson, and Constance Reid, International mathematical congresses: An illustrated history, 1893-1986, Springer-Verlag, New York, 1987. MR874336 (88h:01031)

[2] Atti del Congresso Internazionale dei Matematici, Bologna, 3-10 Settembre 1928 (VI), Bologna, Nicola Zanichelli, 1929-32.

[3] Guillermo P. Curbera, Mathematicians of the world, unite! The International Congress of Mathematicians - a human endeavor; with a foreword by Lennart Carleson, A K Peters Ltd., Wellesley, MA, 2009. MR2499757(2010a:01004)

[4] E. Duporcz (ed.), Compte rendu du Deuxième Congrès Internationale des Mathématiciens, Paris, Gauthier-Villars, 1902. [Earlier in German in Gött. Nachr. (1900) 253-297, and in English in Bull. Amer. Math. Soc. 8 (1902), 437-479].

[5] G. H. Hardy, "David Hilbert", J. London Math. Soc. 18 (1943), 191-192.

[6] Olli Lehto, Mathematics without borders: A history of the International Mathematical Union, Springer-Verlag, New York, 1998. MR1488698 (98m:01039)

[7] Constance Reid, Hilbert, With an appreciation of Hilbert's mathematical work by Hermann Weyl, Springer-Verlag, New York, 1970. MR0270884 (42 \#5767)

[8] Kurt Reidemeister, Hilbert/Gedenkband, Berlin, Springer, 1971. MR0282784 (44 \#18)

[9] A. S. Wightman, Hilbert's sixth problem: mathematical treatment of the axioms of physics, Mathematical developments arising from Hilbert problems (Proc. Sympos. Pure Math., Northern Illinois Univ., De Kalb, Ill., 1974), Amer. Math. Soc., Providence, RI, 1976, pp. 147240. MR0436800 (55 \#9739) 
[10] Benjamin H. Yandell, The honors class: Hilbert's problems and their solvers, A K Peters Ltd., Natick, MA, 2002. MR.1880187 (2003b:01037)

Department of Mathematics and Computer Science, Santa Clara University, 500 El Camino Real, Santa Clara, California 95053-0290

E-mail address: galexand@math.scu.edu 